\title{
In vitro evaluation of fungicide and biocontrol agents against Alternaria helianthi causing leaf blight of sunflower (Helianthus annuus L.)
}

\section{K. ATHIRA}

Department of Plant Pathology, Vanavarayar Institute of Agriculture, Manakkadavu, POLLACHI (T.N.) INDIA

\section{ARITCLE INFO}

Received : 01.07 .2017

Revised : 20.08 .2017

Accepted : 02.09.2017

\section{KEY WORDS :}

Pseudomonas, A. helianthi, Poison food technique, Sunflower, Mancozeb

Email : athirakk@gmail.com

\begin{abstract}
Leaf blight caused by Alternaria helianthi is one of the major diseases of sunflower worldwide. It is responsible for causing upto10-15 per cent yield losses in sunflower. In this study, antagonistic effects of Pseudomonas and Trichoderma isolated from rhizosphere of sunflower were evaluated against Alternaria helianthi as potential biocontrol agents in vitro. Fungal inhibition tests were performed using dual plate culture technique. Overall the culture of Pseudomonas showed the maximum inhibition of 77 per cent on the growth of A. helianthi followed by Trichoderma. Fungicide Dithane M-45 (Mancozeb) was used at three different concentrations of 0.01, 0.05 and $0.1 \mathrm{ppm}$ in inhibiting the radial growth of $A$. helianthi by poison food technique. All the three concentrations of Mancozeb inhibited the radial growth. Among them, Carbendazim at $0.1 \mathrm{ppm}$ was found to be the most effective against the pathogen. The growth parameters (plant height, root length and shoot length) were significantly increased by treating the seeds with bio control agent Pseudomonas compared to the untreated control. Results indicate that PGPR improve growth parameters and can also help in the biocontrol of pathogen.
\end{abstract}

How to view point the article : Athira, K. (2017). In vitro evaluation of fungicide and biocontrol agents against Alternaria helianthi causing leaf blight of sunflower (Helianthus annuus L.). Internat. J. Plant Protec., 10(2) : 333-338, DOI : 10.15740/HAS/IJPP/10.2/333-338. 